\title{
Sorptive removal of disinfection by-product precursors from UK lowland surface waters: impact of molecular weight and bromide
} Irene Carra ${ }^{1 *}$, Javier Fernandez Lozano${ }^{1}$, Scott Johannesen ${ }^{1}$, Max Godart-Brown ${ }^{1}$, Emma H. Goslan $^{1}$, Peter Jarvis ${ }^{1}$, Simon Judd ${ }^{1}$

${ }^{1}$ Cranfield University, College Rd, Cranfield, MK430AL, UK

*Corresponding Author: irene.carra@cranfield.ac.uk; Cranfield University, College Rd, Cranfield, MK430AL, UK

\section{Abstract}

The current study compared the impact of three different unit processes, coagulation, granular activated carbon (GAC), and a novel suspended ion exchange (SIX) technology, on disinfection by-product formation potential (DBPFP) from two UK lowland water sources with medium to high bromide content. Specific attention was given to the influence of the organic molecular weight (MW) fraction on DBPFP as well as the impact of bromide concentration. While few studies have investigated the impact of MW fractions from Liquid Chromatography with Organic Carbon Detection (LC-OCD) analysis on dissolved organic carbon (DOC) removal by different processes, none have studied the influence of DOC MW fractions from this analysis on DBP formation. The impact of higher bromide concentration was to decrease the total trihalomethane (THM) and haloacetic acid (HAA) mass concentration, in contrast to previously reported studies. Results indicated that for a moderate bromide concentration source $(135 \mu \mathrm{g} / \mathrm{L})$, the THM formation potential was reduced by $22 \%$ or $64 \%$ after coagulation or SIX treatment, respectively. For a high bromide content source $(210 \mu \mathrm{g} / \mathrm{L})$, the THM formation potential removal was $47 \%$ or $69 \%$ following GAC and SIX treatment, respectively. The trend was the same for HAAs, albeit with greater differences between the two processes/feedwaters with reference to overall removal. A statistical analysis indicated 
that organic matter of $\mathrm{MW}>350 \mathrm{~g} / \mathrm{mol}$ had a significant impact on DBPFP. A multiple linear regression of the MW fractions against DBPFP showed a strong correlation $\left(\mathrm{R}^{2}\right.$ between 0.90-0.93), indicating that LC-OCD analysis alone could be used to predict DBP formation with reasonable accuracy, and offering the potential for rapid risk assessment of water sources.

Keywords: ion exchange; molecular weight; organic matter; LC-OCD; disinfection byproducts 
Declarations of interest

Declarations of interest: none 


\section{Introduction}

Natural organic matter (NOM), or more generically dissolved organic carbon (DOC), if all organic matter is considered, can be substantially removed by coagulation/clarification in large-scale potable water treatment works (WTWs). Alternatively, granular activated carbon (GAC) can be employed at the start of the process as a "roughing" filter for organic matter removal $[1,2]$. However, GAC is limited in its efficacy with reference to the adsorptive capacity of the media [3] and its overall DOC removal capability $[2,4]$.

In reality, neither conventional coagulation-clarification $n \curlyvee r$ sughing GAC are usually capable of reliably meeting the regulated water quality $\leqslant$ tá. ${ }^{2}=$ :ds for the more challenging of the DOC-laden surface waters. This relates to tre LOC physicochemistry, and a very significant research effort has been dedicated th the currelation of disinfection by-product formation potential (DBPFP) with the physice arı chemical fractional content of DOC. It is often the case that the DOC fraction - untributing most significantly to DBPFP is the hydrophobic (HPO) fraction, which in also the fraction most extensively removed by conventional clarification [5-7]. Nol vi.hstanding this, the concentration of the residual hydrophilic (HPI) fraction is oft 2 n s.fficient to generate levels of DBPs above the permitted limits [6]. For water source: co itaining a substantive amount of hydrophilic DOC, reducing

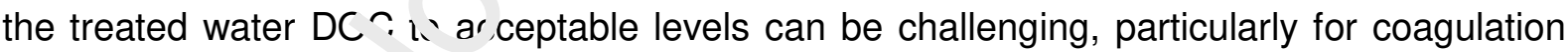
processes. Lowland sur ${ }^{\text {fce }}$ ce water sources in the UK would fit into this category.

Of the different technologies studied/implemented for supplementary DBP precursor removal, ion exchange (IEX) presents an alternative adsorptive process to activated carbon which provides a greater capacity for DOC on a mass basis [8,9]. Various IEX-based processes, including magnetic ion exchange (MIEX) and suspended ion exchange (SIX), and a wide range of other sorption media [10] have been successfully demonstrated to suppress formation of both THMs and HAAs $[9,11-14]$ in treating of NOM or its analogues. Of the 
published papers on the area, many have either been based on practical performance in terms of DOC removal $[15,16]$ or DBP precursor removal $[11,14,17]$, with many favouring physico-chemical fractionation for characterisation of the DOC [18-20].

Trihalomethanes (THMs) and haloacetic acids (HAAs) remain the most extensively studied of all halogenated DBPs in potable water treatment [21]. However, the most recent focus on brominated and iodinated DBPs has, as with HAAs over THMs, been prompted by evidence of the increased cytotoxicity and genotoxicity of these spec os compared with chlorinated equivalents. In addition, the drinking water guideline $v$ alut; from the World Health Organisation (WHO) tend to be lower for brominate' $\mathrm{D}_{\mathrm{B}} \mathrm{PS}$ when compared to fully chlorinated equivalents [22]. Studies of brominated ZBr's pertaining to IEX technologies have included targeted removal of bromide $[6,23]$ as a means of suppressing brominated DBP formation directly. Those in which imra c sf raw water bromide concentration on treated water DBP speciation have be $n$ l'rgely limited to bench-scale studies $[11,13,24]$. Reported outcomes across all studie , have been inconsistent. Most authors have reported an increase in total DBP concentrat.J' $\mathrm{V}$ 'ith increasing bromine substitution (the proportion of brominated species making ip the total DBP concentration) [25-27]. Conversely, and counter-intuitively, others $\left[14,\left\llcorner^{2}\right]\right.$ have reported a decrease, with some recent indication of the trend depending on t $\mathrm{fe}$ ecise precursor [29].

Few of these papers have studied the impact of molecular weight (MW) fractions on DOC removal by novel and conventional processes [14,17], and studies of both DBPFP and DBP yield (FP/DOC concentration) have been largely based on chemical characterisation. Moreover, none have investigated the potential influence of DOC MW fractions from LC-OCD analysis on DBP formation, which could provide the Water Industry with an additional tool to characterise water sources and their potential risk for DBPFP. Lastly, no previous papers have combined the study of MW fractionation with bromide concentration impacts on the distribution of chlorinated and halogenated DBPs. The current study, based on real UK 
surface waters, compares the impact of three different unit processes, GAC, and SIX technology, on DBPFP. Specific attention was given to the influence of the organic MW fraction on THM and HAA FP, the comparative efficacy of the conventional coagulation and GAC processes, and the possible impact of feedwater bromide concentration.

\section{Methodology}

\subsection{Water samples}

Water samples were collected from two WTWs in the UK. The samples from each WTW was collected within a six-week period to avoid seasonal impact c ، ine iesults. One of the WTWs (Res) abstracts from a large reservoir, characterised as : "lo 'land reservoir". The treatment train comprises primary ozonation, coagulation and nus:ator-clarification and rapid gravity filtration for removal of bulk organic matter and susp 'ided particles; secondary ozonation and GAC adsorption for pesticide removal; al $\mathrm{N}$ c lloramination (Fig S1). The other WTW (Riv) is considered to have a "lowland $r$ 'ver source. Treatment on site consists of roughing GAC adsorption and ultrafiltration :nembraıles for bulk organic removal and suspended particles; UV/peroxide and GAC ar sr, ${ }^{+}$: on for pesticide removal; and UV disinfection and residual chlorination (Fig S1). Ti: ? raw water was characterised (Table 1) and samples were taken downstream of the cla, fication process (Res) and GAC filter (Riv) (Fig S1) to allow comparison of treatmer $\mathrm{e}_{\mathrm{i}}{ }^{\mathrm{i} i \mathrm{c} a c y}$ from these conventional processes to that of SIX. The coagulation process ( $\mathrm{Re}_{\mathrm{i}}$ ) used ferric sulphate as coagulant at a concentration of $3.5 \mathrm{mg} / \mathrm{L}$ Fe. The GAC treatment (Riv) had an empty bed contact time of 20 min and used TL830 as media. 
Table 1. Average and standard devation of raw water characteristics for the lowland reservoir and river sources

\begin{tabular}{lcc}
\hline Parameter & $\begin{array}{c}\text { Lowland reservoir } \\
(\text { Res })\end{array}$ & $\begin{array}{c}\text { Lowland river } \\
(\text { Riv })\end{array}$ \\
\hline DOC $(\mathrm{mg} / \mathrm{L})$ & $5.6 \pm 0.1$ & $6.0 \pm 0.1$ \\
$\mathrm{pH}$ & $8.4 \pm 0.1$ & $8.3 \pm 0.1$ \\
Alkalinity $(\mathrm{mg} / \mathrm{L})$ & $192 \pm 1$ & $162 \pm 1$ \\
Bromide $(\mu \mathrm{g} / \mathrm{L})$ & $135.0 \pm 0.2$ & $210.0 \pm 0.2$ \\
\hline
\end{tabular}

\section{$2.2 \mathrm{SIX}$ jar tests and resin conditioning}

The resin used was Lewatit® S 5128 (Lanxess, Ger: ‘anı), a Type 1 strong basic anion resin with an acrylic gel structure and an adsorpt'vl capacity of $1.8 \mathrm{eq} / \mathrm{L}$, according to the manufacturer specifications. A previousl:, resented methodology [24] was used for preparation (conditioning) of the virgin $r_{-} \cdot n$ : prior to use and following each test the resin was first washed with deionised (DI) 'waı $r$, then regenerated with a $100 \mathrm{~g} / \mathrm{L}$ sodium chloride

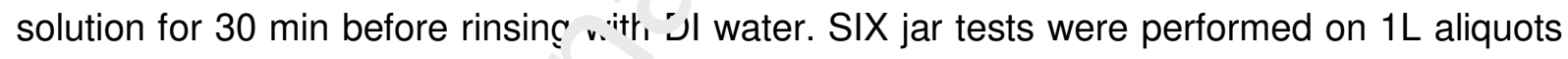
of raw and treated samples ising a paddle jar tester and following the methology of Finkbeiner et al. [24]. Three : ss n concentrations were tested, 10, 20 and $30 \mathrm{~mL} / \mathrm{L}(7.3,14.6$, $21.9 \mathrm{~g} / \mathrm{L}$, respectively), ' $\mathrm{N}_{\mathrm{L}} \mathrm{L}$ '. sampling times of 10,20 and $30 \mathrm{~min}$ and duplicate tests for each test condition. The maxırnum concentration of resin tested was set at $30 \mathrm{~mL} / \mathrm{L}$ as that is the operational limit at larger scale for high flows in the SIX process. All water samples were prefiltered to $0.45 \mu \mathrm{m}$ before analysis.

\subsection{Analysis}

\subsubsection{Chemical}

Chemical fractionation using non-ionic microporous resins [30] was carried out on both raw waters sampled over the same six-week period (June-July) to discount any seasonal 
impacts. Two litres of water sample were passed through two $60 \mathrm{~mL}$ columns in tandem to determine the organic composition. The first column contained XAD7-HP resin, which preferentially adsorbs the hydrophobic fraction (HPO), and the second column with XAD4 resin, which adsorbs the transphilic (TPI) fraction. Organic compounds not adsorbed by either column were classified as the hydrophilic (HPI) fraction. Resins were back-eluted with $0.1 \mathrm{M} \mathrm{NaOH}$ and cleaned with deionised water and $\mathrm{HCl}$ at $0.5 \%$, yielding over $80 \%$ recovery. The resins were Soxhlet-extracted with methanol before first use and conditioned before each run by cleaning with water followed by $0.1 \mathrm{M} \mathrm{NaOH}$ and $\mathrm{C} 1 \mathrm{M} \mathrm{HCl}$.

DOC was measured using a Shimadzu TOC-V analyser $\mathrm{n}$ ith é non-purgeable organic carbon

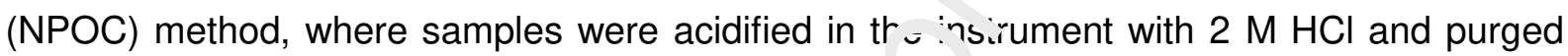
with carbon-free air to remove $\mathrm{CO}_{2}$-derived carbon'stes and bicarbonates. The method was calibrated to measure DOC in the $1-10 \mathrm{mg} / \mathrm{L}$ ia. $\mathrm{nf}$. Blanks and quality control checks were analysed every five samples, with all $\varepsilon$ ral ses being duplicated. The limit of quantification (LOQ) was $1 \mathrm{mg} / \mathrm{L}$.

DBP formation potential tests ' $v$ t? performed on raw water and treated samples. Samples were diluted with ultrapure $\mathrm{w}^{\text {ther }}$ to $1 \mathrm{mg} / \mathrm{L}$ DOC using a $\mathrm{Cl}_{2}: \mathrm{DOC}$ mass ratio of $5: 1$ (0.07:0.08 molar ratin al $d \mathrm{C} J \mathrm{C}$ as $\mathrm{C})$, the free chlorine measured using DPD reagent [31]. The chlorinated samples vere stored in $100 \mathrm{~mL}$ PTFE bottles with no headspace in the dark for $7 \mathrm{~d}$, and the residual chlorine then quenched with sodium sulphite or ammonium chloride for THM or HAA analysis, respectively. The THMs species analysed comprised trichloromethane (TCM), tribromomethane (TBM), bromodichloromethane (BDCM) and chlorodibromomethane (CDBM). The HAAs analysed were monochloroacetic acid (MCAA), dichloroacetic acid (DCAA), trichloroacetic acid (TCAA), monobromoacetic acid (MBAA), dibromoacetic acid (DBAA), tribromoacetic acid (TBAA), bromochloroacetic acid (BCAA), bromodichloroacetic acid (BDCAA), and dibromochloroacetic acid (DBCAA). An Agilent GCECD 6890 with a capillary column (Phenomenex $30 \mathrm{~m} \times 0.25 \mathrm{~mm} \times 0.25 \mu \mathrm{m}$ ) was used for 
chromatographic analysis, following a modified USEPA extraction method (551.1 and 552), as used previously [32]. The LOQ for each DBP was $1 \mu \mathrm{g} / \mathrm{L}$, with the exception of MCAA (LOQ $2 \mu \mathrm{g} / \mathrm{L})$.

LC-OCD analysis by the Het Water Laboratorium (Netherlands) was conducted to determine organic matter MW distribution before and after treatment, following the method of [33]. The column used for this analysis had a separation range up to $10,000 \mathrm{~g} / \mathrm{mol}$, with the $\mathrm{MW}$ decreasing with elution time. The fastest-eluting compounds $\mathrm{h}$ »'е a MW above 10,000 g/mol and are considered hydrophilic since they exhibit no interar tior, with the cation-exchanging column. The compounds in this group are not usually dett stak'e by UV, and thus have few or no unsaturated chemical bonds. However, it has $k_{-} u^{n}$, zported [33] that they may show some response to the organic nitrogen detector, in ïicaing polysaccharides with $\mathrm{N}$ material and possibly proteinaceous material. The sec ı. ' r zak has been associated with humic-like substances (ca 1,000 g/mol) [33]. The tr rd jroup has been identified as breakdown products from humic-like substances (300-500 $₫ / \mathrm{mol})$. The next group eluted are low MW-acids $(<350$ $\mathrm{g} / \mathrm{mol}$ ) followed by low MW neutrals (z $(\mathrm{s}$, $<350 \mathrm{~g} / \mathrm{mol})$.

\subsubsection{Statistical Analysin}

Multiple linear regrec -io, an alysis and analysis of variance was performed using MiniTab® statistical software (Mir:+ז.o, LLC State College, Pennsylvania, USA) at a significance level of 0.05. The statistical analysis was expanded to include the dataset from this research and that published by Metcalfe et al. [14] and Finkbeiner et al. [17].

\section{Results and discussion}

\subsection{Water Chemistry}

Results of the hydrophobicity-based fractionation analysis (Fig. 1a) revealed a higher HPO content in the Res source (52\%) compared with the Riv source (43\%). Moreover, in the Riv 
source the HPI fraction accounted for almost half of the organic content, compared with $30 \%$ for the Res sample. Results also showed more than twice the amount of TPI fraction in the Res than in the Riv source (18\% vs $8 \%$ ).

DOC removal from the raw water sources by SIX was explored at resin concentrations of 10$30 \mathrm{~mL} / \mathrm{L}$ (Fig 1b) by way of characterising the organic matter chemistry. While the initial DOC content of the water sources was similar, SIX proved to be more efficient at removing Riv sample DOC, providing $60 \%-75 \%$ removal compared with $30,-50 \%$ for the Res source. The pseudo-first order kinetic constants (Table S1) supported thi ; fact. The constant for $10 \mathrm{~mL} / \mathrm{L}$ resin was almost four times higher in the Riv source (0.112 s $\left.0.44 \mathrm{~min}^{-1}\right)$, ca. three times higher for $20 \mathrm{~mL} / \mathrm{L}\left(0.022\right.$ vs $\left.0.61 \mathrm{~min}^{-1}\right)$, and more th. a tw. ice for $30 \mathrm{~mL} / \mathrm{L}\left(0.27\right.$ vs $0.65 \mathrm{~min}^{-}$ $\left.{ }^{1}\right)$ resin. This further indicates differing chemist.ies, the Riv water containing higher

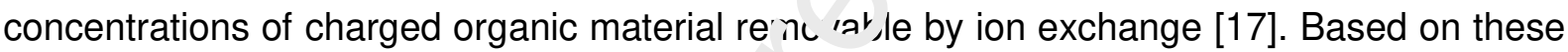
results, a dose of $30 \mathrm{~mL} / \mathrm{L}$ was selectec' for subsequent trials and analysis as it provided the highest removal of DOC.

(a)

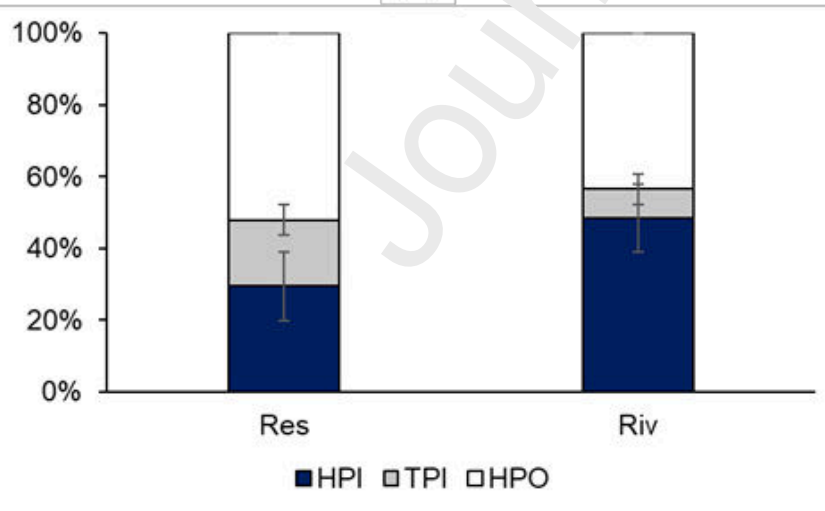

(b)

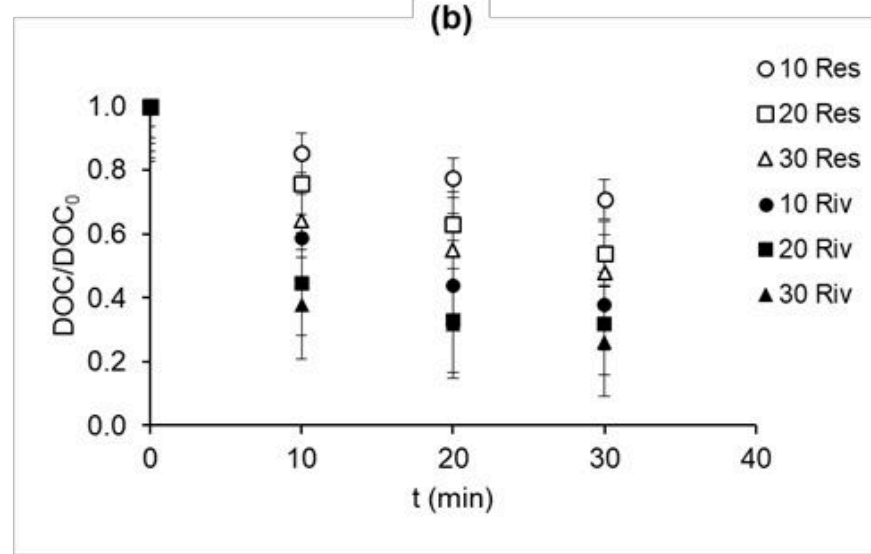

Figure 1. Outcomes of DOC chemical analysis of Res and Riv sources (a) Organic fraction make-up, and (b) DOC removal transients at three SIX doses (in $\mathrm{mL}$ resin/L), jar testing. Error bars represent the standard error of the mean. 


\subsection{DOC molecular weight distribution trends}

Recorded DOC molecular weight distributions within the bands of $>10,000, \sim 1000,300-500$ and $<350 \mathrm{~g} / \mathrm{mol}$ (Fig. 2) indicated that the size fraction at around $1000 \mathrm{~g} / \mathrm{mol}$ dominated for all raw water and pre-SIX treated samples. The two raw water samples were similar in terms of total DOC concentration (5.6 and $6 \mathrm{mg} / \mathrm{L}$ for the Res and Riv sources respectively) and the proportion of the dominant $\sim 1000 \mathrm{~g} / \mathrm{mol} \mathrm{MW}$ fraction $(50 \%$ and $60 \%$ for the Res and Riv sources, respectively). The main difference was in the percentage of the largest $>10,000$ $\mathrm{g} / \mathrm{mol}$ fraction, which was $16 \%$ and $8 \%$ respectively for thi Res and Riv sources. The molecular weight distribution was shifted towards higher valı əs f $r$ the Res samples. No lowMW acid organics were detected for either source. Th ' th $\supset$ water sources can thus be regarded as being comparable in quality with resp $=\mathrm{Cl}$ to $\mathrm{MW}$ distribution and DOC level, notwithstanding the substantially different sources a. Id su'Jsequent chemistries (Fig. 2).

Differences in removal across the fou " AW fractions were observed between the two processes. Whereas clarification of the Res source removed only $25 \%$ of the DOC, predominantly in the two largest sizf $r$ anges $(46 \%$ and $30 \%$ for the $>10,000$ and $\sim 1,000$ $\mathrm{mg} / \mathrm{L}$ fractions respectively), GAC removed $50-60 \%$ of the DOC across all size fractions. In absolute terms the remova' car -.bility of the GAC was 2.6 times that of clarification, with 3.4 $\mathrm{mg} / \mathrm{L}$ of DOC being *am. vver compared with $1.3 \mathrm{mg} / \mathrm{L}$ for clarification. For the predominant $\sim 1,000 \mathrm{MW}$ size fracticn removals were $31 \%(0.8 \mathrm{mg} / \mathrm{L})$ and $55 \%(2 \mathrm{mg} / \mathrm{L})$ for the Res and Riv waters, respectively.

The largest MW group (> 10,000) has been reported to primarily contain biopolymers, such as polysaccharides, amino-sugars or proteins, but it might also contain a low proportion of aromatic moieties, with previous studies confirming that coagulation preferentially removes this fraction [14]. The second largest group $(1,000 \mathrm{mg} / \mathrm{L})$ is typically constituted by humic-like substances [33], with complex chemical structures, charged and hydrophobic [34], also 
justifying their removal by coagulation. However, organics with $\mathrm{MW}>350 \mathrm{~g} / \mathrm{mol}$ are known to contain building blocks of humic-like substances, more hydrophilic, and less efficiently removed by coagulation [14]. On the other hand, whilst MW fractions smaller than 1,000 $\mathrm{g} / \mathrm{mol}$ have been shown to be efficiently removed by GAC, the larger size of organics with MW $>10,000 \mathrm{~g} / \mathrm{mol}$ prevents them accessing adsorption sites [3,35]. This is in contrast with the present study, where the largest fraction was also efficiently removed, although this can be attributed to frequent regeneration of the GAC on site (bimonthly), making adsorption sites available.
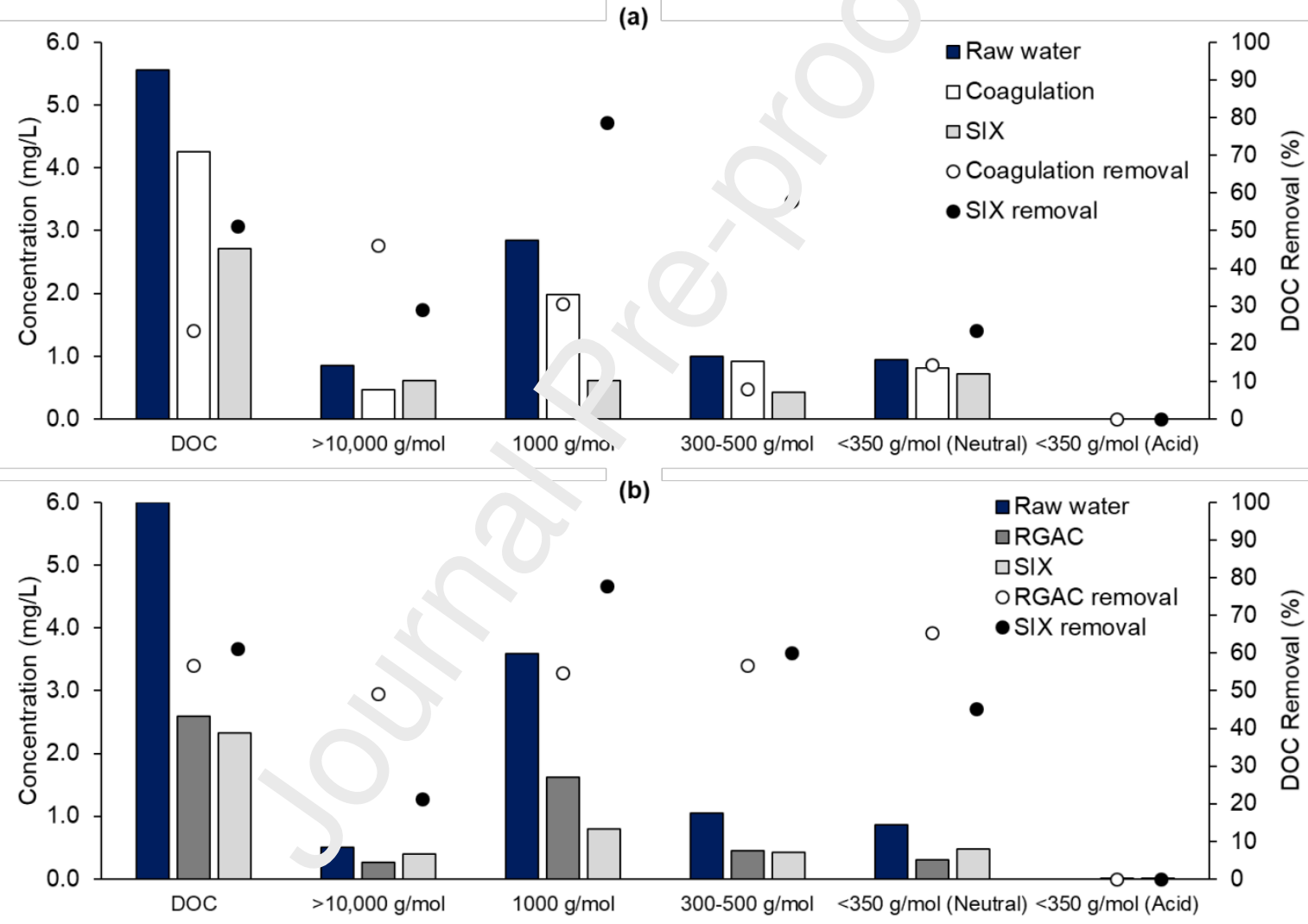

Figure 2. Organic matter concentration and MW fractions of raw and treated waters for (a) Res and (b) Riv sources.

SIX removed $51-61 \%$ of the DOC from both raw water sources, with $78-79 \%$ removal of the predominant $\sim 1000 \mathrm{~g} / \mathrm{mol}$ fraction and $58-60 \%$ for the $300-500 \mathrm{~g} / \mathrm{mol}$ fraction. These two groups contain similar acidic, negatively charged functional groups, which makes them amenable to SIX treatment [36]. Removals of the largest and smallest fractions revealed 
slightly differing propensities, with slightly greater removal of the $>10,000 \mathrm{~g} / \mathrm{mol}$ fraction for the Res source (29\% vs $21 \%$ ) and the reverse trend (45\% vs. $24 \%$ ) for the $<350 \mathrm{~g} / \mathrm{mol}$ neutral fraction. This can be attributed to the fact that the $>10,000 \mathrm{~g} / \mathrm{mol}$ fraction blinds the adsorption sites for the $<350 \mathrm{~g} / \mathrm{mol} \mathrm{MW}$ compounds. This is consistent with that seen for SIX treatment of DOC from an upland source [37] and for GAC [3] such that these organic compounds are less readily removed compared to the same size fraction in the Riv source.

Recorded differences in bulk organic removal relate to diff(rences in both the treatment technology and the organic matter chemistry such as cor ıpo nd hydrophobicity (Section 3.1), as well as the molecular functional chemistry of the [ OC in each MW fraction.

\subsection{DBP precursor removal trends}

\subsubsection{THMFP}

In keeping with the DOC removal trends ' ${ }^{\circ}$ ig. 2), twice the total THM (tTHM) precursors were removed by the GAC process fo the iriv source (47\%) than by the clarification process for the Res source (23\%) (Fig. 3a ana 3b). This is in line with reported DOC removal by nonenhanced coagulation and a vo rption [3,38-41]. The tTHM precursor removals for the Res source (Fig. 3a) follow a :...dt of the DOC removal trends (Fig. 2a). The formation potential was reduced by $23 \%$ or $64 \%$ respectively, and such that the overall yield (tTHM/DOC) was constant throughout the process at 38-39 $\mu \mathrm{g} / \mathrm{mg}$ (Fig. 3c). On the contrary, for the Riv source the overall DBP yield decreased (Fig. 3d) by $27 \%$ or $38 \%$ following GAC and SIX treatment, respectively, with an associated formation potential reduction of $47 \%$ and $69 \%$ (Fig 3b). 
(a)

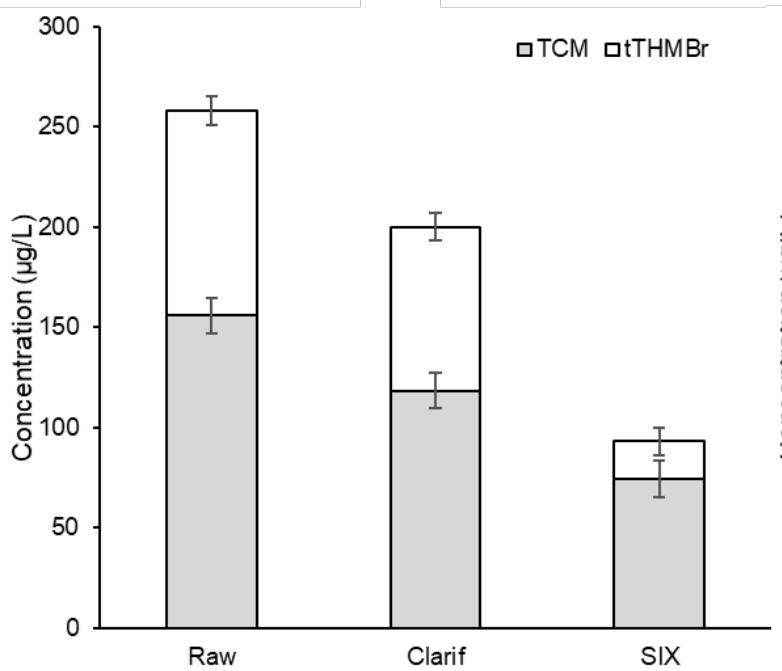

(c)

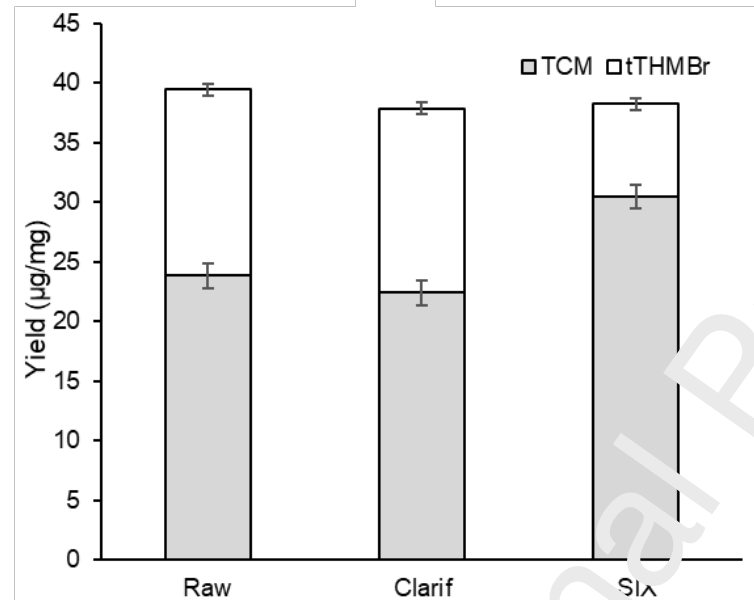

(b)
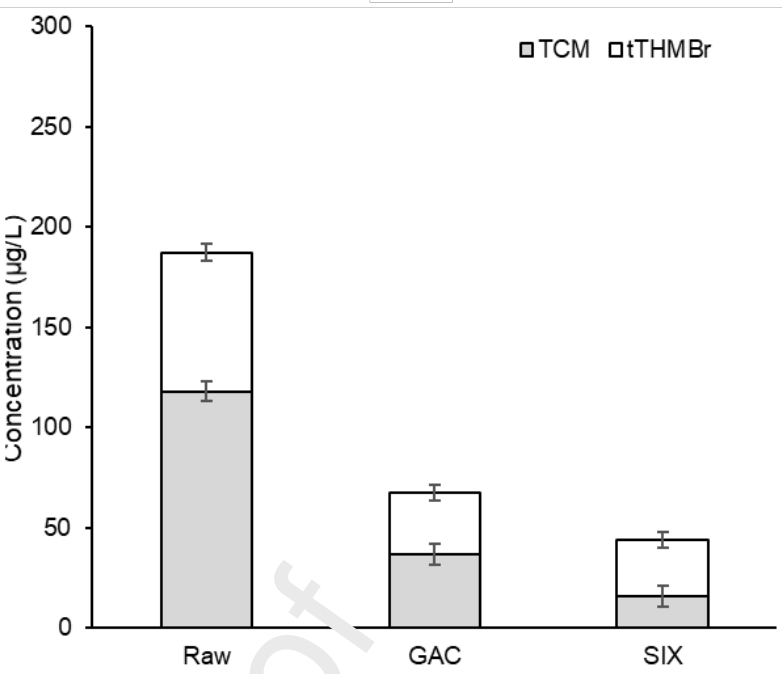

(d)

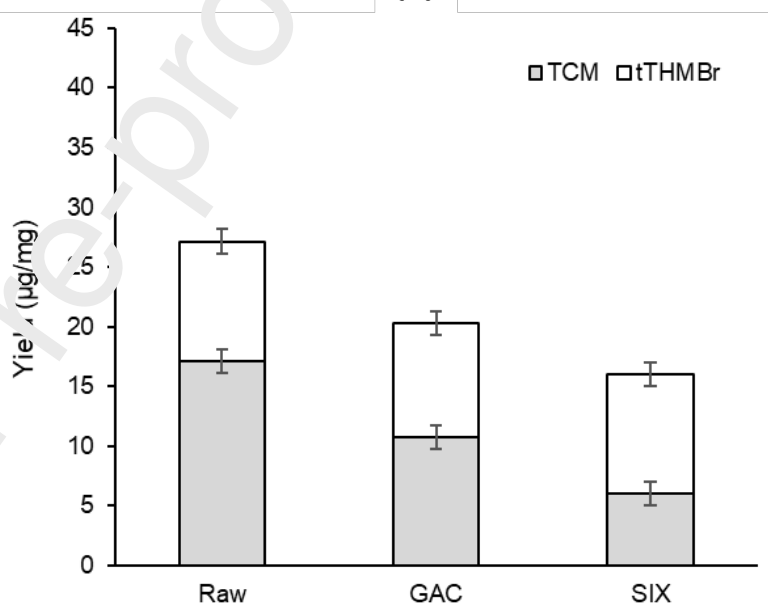

Figure 3. Distribution of TH↔: concentration and yield, TCM and brominated species $\left(\mathrm{tTHM}_{\mathrm{Br}}\right)$, comprising BDC!1, こDBM and TBM, for (a, c) Res and (b, d) Riv sources. Error bars represent the sta. Jard error of the mean.

Trends in the distribution of chlorinated and brominated species differed significantly between the two raw waters. For the lower-bromide concentration (Res source) the TCM yield was unchanged following clarification $(22 \mu \mathrm{g} / \mathrm{mg})$, showing that both primary ozonation and clarification had no impact on the yield, and increased following SIX treatment (31 $\mu \mathrm{g} / \mathrm{mg}$ ) (Fig. 3c). The yield for the total brominated species (tTHM $\mathrm{Br}_{\mathrm{Br}}$ ), comprising BDCM, CDBM and TBM, remained constant after clarification $(16 \mu \mathrm{g} / \mathrm{mg})$, but decreased following 
SIX treatment for this source $(8 \mu \mathrm{g} / \mathrm{mg})$. For the Riv source, with the higher $\mathrm{Br}^{-}$level, the tTHM $_{\mathrm{Br}}$ yield remained unchanged after GAC or SIX treatment $(9-10 \mu \mathrm{g} / \mathrm{mg})$ (Fig. 3d). However, the TCM yield for this source decreased throughout the process from $17 \mu \mathrm{g} / \mathrm{mg}$ in the raw water to $11 \mu \mathrm{g} / \mathrm{mg}$ after GAC or to $6 \mu \mathrm{g} / \mathrm{mg}$ after SIX treatment (Fig. 3d). The treated Riv water THMs thus had a significantly greater $\mathrm{Br}$ content - with an atomic mass more than double that of $\mathrm{Cl}$. Yet it provided a lower mass concentration and yield of tTHMs than that of the Res source, which had a lower bromide concentration. It should also be pointed out that bromide was not removed by either coagulation (Res source! or GAC (Riv source), with < $11 \%$ removed by SIX (Res and Riv source).

Whilst this observation is counter-intuitive, in that higt.w. ${ }_{1}$ : $\mathrm{IM}$ levels would be expected from higher feed bromide concentrations [25-27], simile: tru nds have been reported previously $[14,28]$. As with the current study, these two sth tif $;$ were based on real UK surface waters with bromide levels substantially lower nar. the DOC concentrations. The reported work of Szczuka et al. [25] and Cai et al. [2ך], on the other hand, were based either on groundwater with seawater intrusion with high€: $3 \mathrm{r}$ LOC ratios or desalinated seawater blended with drinking water.

A possible explanation $c^{+}$the THM trends is provided from the dynamic molar yield trends $Y_{d}$ $=\mathrm{d}[\mathrm{THM}] / \mathrm{d}[\mathrm{DOC}]$ (Fig 4a), where the DOC was that of the raw water (Res or Riv) and the treated water (clarification, GAC or SIX). $Y_{d}$ in $\mu \mathrm{M} \triangle \mathrm{DBP}$ per $\mathrm{mM} \Delta \mathrm{DOC}$ varied from 0.7 to 2.4 $\mu \mathrm{M} / \mathrm{mM}$, with the highest values (1.9-2.4 $\mu \mathrm{M} / \mathrm{mM})$ obtained for TCM formation and the lowest for tTHM $\mathrm{Br}_{\mathrm{Br}}(0.7-1.5 \mu \mathrm{M} / \mathrm{mM})$. The $Y_{d}$ for the brominated DBPs was shallower than the TCM slope, indicating that the $\mathrm{THM}_{\mathrm{Br}}$ formation propensity from the halogenated intermediates was substantially lower than that for TCM formation.

However, the effect of the higher $\mathrm{Br}^{-}$levels in the Riv source appears to offset the TCM slope, i.e. the change in the y axis intercept, by $\sim 0.27 \mathrm{mM}$ DOC $(3.2 \mathrm{mg} / \mathrm{L})$. This offset 
suggests that the organic matter preferentially reacts with $\mathrm{HOBr}$ (formed from $\mathrm{HOCl}$ and $\mathrm{Br}^{-}$) to produce intermediates, but that these intermediates are not converted to $\mathrm{THM}_{\mathrm{Br}}$ products as readily as the chlorinated intermediates are converted to TCM. This behaviour has been previously modelled by Mok et al. [42] who studied the reactions undertaken by an activated carbon atom and the steps required to produce chlorinated, brominated and mixed THMs. They demonstrated that the key to determining the species formed is the initial $\left[\mathrm{HOBr}^{-}\right.$ ]:[HOCl$]$ ratio, with a tipping point at $[\mathrm{HOBr}] /[\mathrm{HOCl}]>0.03$, where brominated $\mathrm{THMs}$ dominate. The initial $\left[\mathrm{HOBr}^{-}\right] /\left[\mathrm{HOCl}^{-}\right]$ratios for this study wer $\cdot 9.004$ and 0.006 for the Res and Riv, respectively, which explains the dominance of chlor, for , observed in this study.

The formation of intermediate DBPs has been sur,ycsted by Li et al. [43] who reported aromatic-based DBP intermediates, with the cytotJxic.+y of the brominated intermediates being higher than that of the chlorinated ones F. rtr er to this, Jiang et al. [44] have proposed pathways for the formation of haloger ter. aliphatic DBPs (e.g. THMs and HAAs) which identified the formation of non-halog nated and halogenated aromatic DBPs prior to their degradation to halogenated alipha.ir L'ßPS. The chlorine dose was a strong influencing factor on the formation of the intt-mediate DBPs governing the levels at which they formed. In terms of toxicity, recentlv, a $a_{i}$ approach has been taken to assess the toxicity of a water sample in terms of the $r$ lati e cytotoxicity and genotoxicity of DBPs rather than the mass of the DBPs measured [45]. Although the present study looked solely at THMs and HAAs, there are a number of DBP groups (e.g. haloacetonitriles, haloacetamides, halonitromethanes, haloketones and iodinated compounds) that contribute towards the cytotoxicity and genotoxicity of a water sample and it is acknowledged that the values for THMs and HAAs are generally lower than the listed compounds. In terms of mass, the THMs and HAAs can dominate the DBPs formed but when assessed according to Li and Mitch [45], the other compounds found at lower concentrations can dominate the calculated toxicity of the water. This has been further explored by Cuthbertson et al. [46] who used similar calculations to determine whether GAC treatment produced water with lower cytotoxicity and 
genotoxicity. Further research is needed to address the role of different treatment processes such as adsorption on these emerging DBP groups and their link with LC-OCD MW groups.

(a)

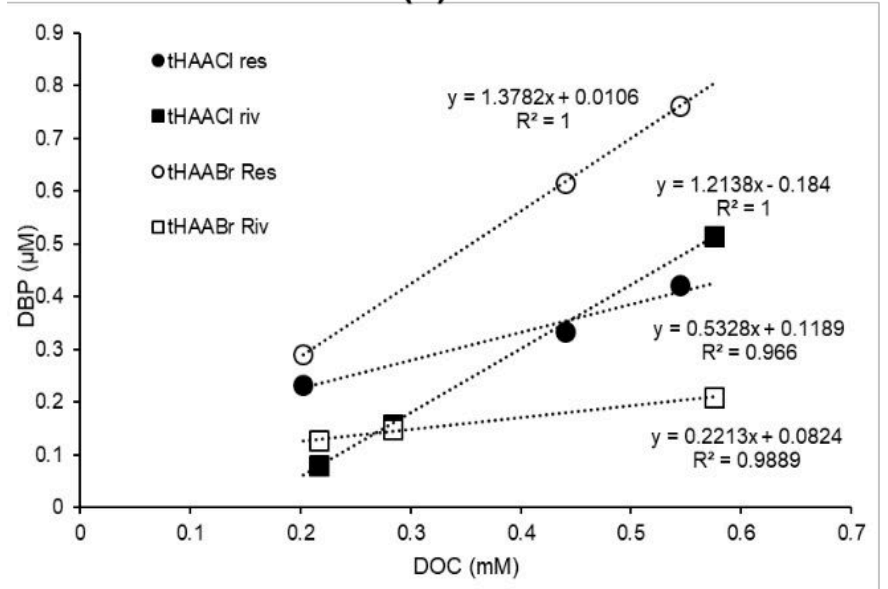

(b)

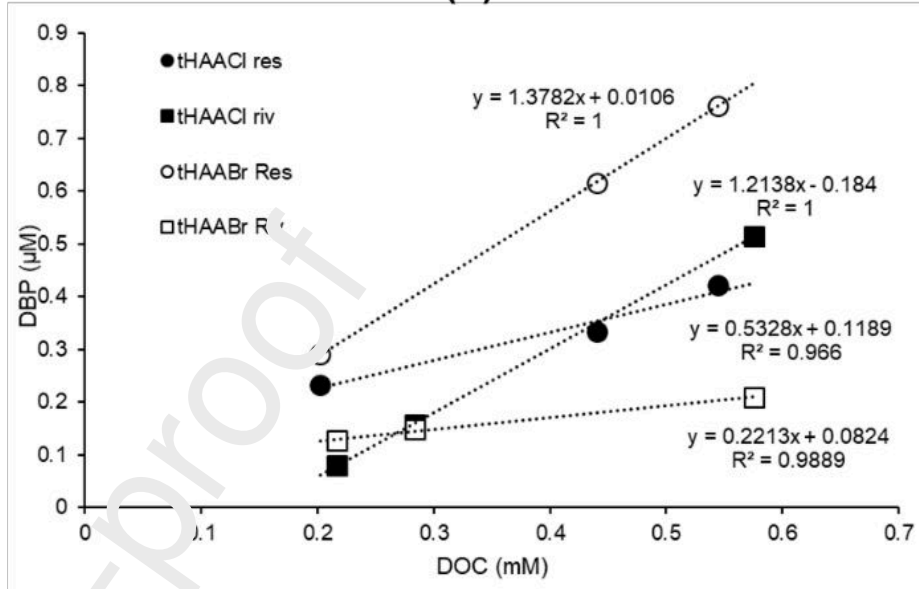

Figure 4. Dynamic molar yield trends: (a) $m$ sia $T$. IM concentration vs DOC concentration for TCM and brominated species $\left(\mathrm{tT}^{\prime}{ }^{\prime} \mathrm{Mr}_{\mathrm{r}_{i}}\right)$; and (b) molar HAA concentration vs DOC concentration for chlorinated (tHAACi, and and brominated species (tHAABr) in the Res and Riv sources.

\subsubsection{HAAFP}

Trends in total HAA $: 0$, ser tration and HAA speciation (Fig. 5) were similar to those of THMs. For the Res $\mathrm{sc}^{\cdots}$ 'e the concentration of both the chlorinated and the halogenated species decreased from $206 \mu \mathrm{g} / \mathrm{L}$ to $165 \mu \mathrm{g} / \mathrm{L}$ following clarification or decreased further following SIX treatment (103 $\mu \mathrm{g} / \mathrm{L})$ (Fig. 5a), such that the overall yield was constant at around 33-34 $\mu \mathrm{g} \mathrm{tHAA} / \mathrm{mg} \mathrm{DOC} \mathrm{(Fig.} \mathrm{5c),} \mathrm{although} \mathrm{the} \mathrm{halogenated} \mathrm{yield} \mathrm{after} \mathrm{SIX} \mathrm{treatment}$ was slightly lower than in the raw water or clarification (18 vs $22 \mu \mathrm{g} / \mathrm{mg}$ DOC). As with the THM yield trends the proportion of chlorinated byproducts increased following SIX treatment for the Res water from $10 \mu \mathrm{g} / \mathrm{mg}$ to $15 \mu \mathrm{g} / \mathrm{mg}$ (Fig. 5c). Also, for the Riv source both the tHAA concentration (Fig. 5b) and the yield (Fig. 5d) were significantly lower (by almost 50\%) 
than the corresponding values for the Res source and decreased with increasing brominated DBP content. However, in this case the yield increased after GAC (9 $\mu \mathrm{g} / \mathrm{mg})$ or SIX (10 $\mu \mathrm{g} / \mathrm{mg})$ in comparison to the raw water $(6 \mu \mathrm{g} / \mathrm{mg})$, a trend similar to that seen for the THMs (Fig. 3).

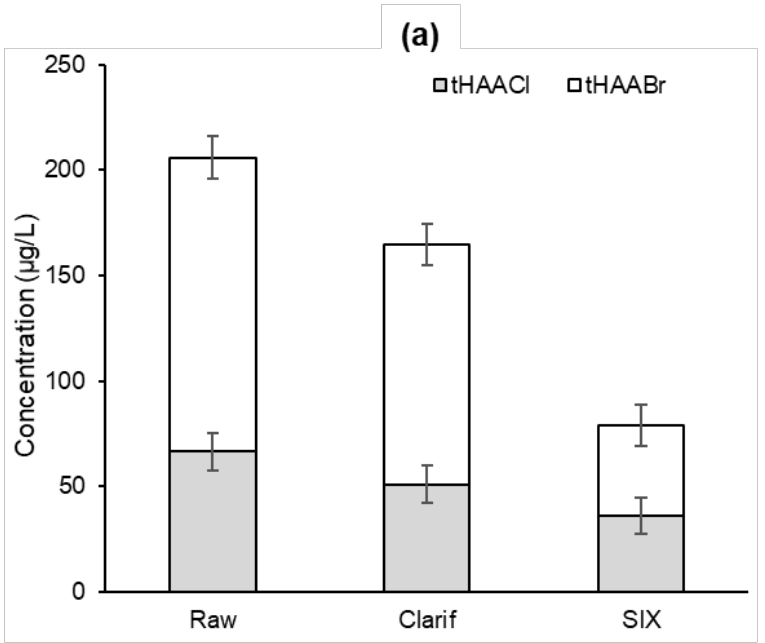

(c)

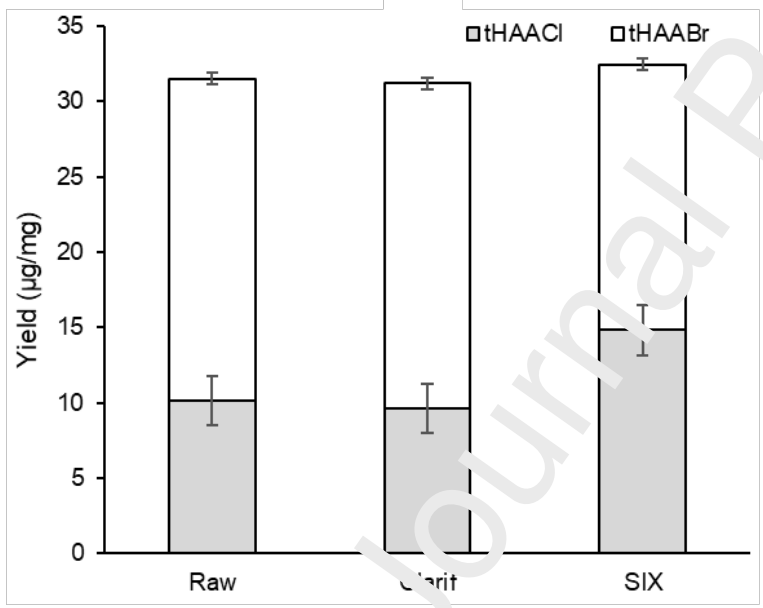

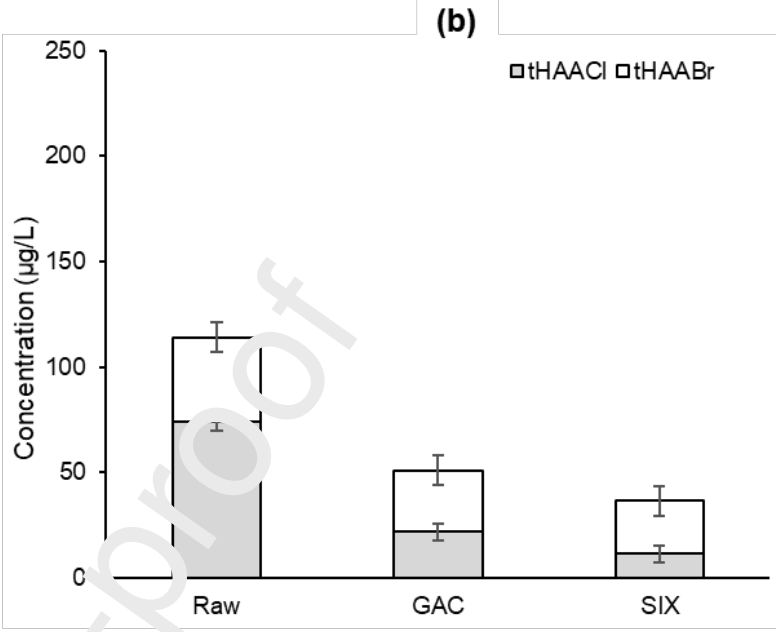

(d)

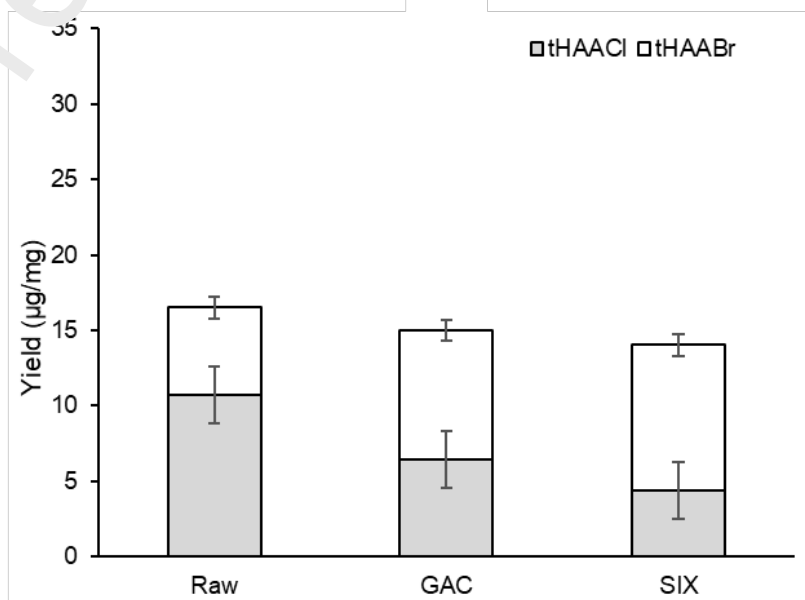

Figure 5. Distribution of $\mathrm{HAA}$ concentration and yield, $\mathrm{tHAA}_{\mathrm{Cl}}$ comprising $\mathrm{MCAA}$, DCAA, TCAA, and $\mathrm{HHA}_{\mathrm{Br}}$ comprising MBAA, BCAA, DBAA, BDCAA, DBCAA, and TBAA for (a, c) Res and (b, d) Riv sources.

On the other hand the dynamic molar yield trends $\Delta[\mathrm{HAA}] / \Delta[\mathrm{DOC}]$, whilst substantially linear $\left(R^{2}=0.966-1.00\right)$, did not follow the same trend as for the THMs (Fig. 4b). For the HAAs, the steepest slopes were recorded for the Res source brominated DBPs and the Riv source chlorinated products (Fig. 4b) due to the fact that the brominated yield (Fig. 5b) was greater 
than the chlorinated yield in each source. For example, for the Res source brominated THM yield was between $20-40 \%$ of the total yield; while the brominated HAA yield was between 54-68\%. A significant offset of $0.37 \mathrm{mM}(4.5 \mathrm{mg} / \mathrm{L} \mathrm{DOC})$ between the Res and Riv samples for the chlorinated DBPs is evident, but this relates to the significant difference in slopes (1.21 vs $0.22 \mu \mathrm{M} / \mathrm{mM} \mathrm{DOC}$ ) rather than the intercept alone as with the THM data.

\subsection{DBP precursor removals and MW distribution}

A statistical analysis comprising an Analysis of Variance (AviVA) and a multiple linear regression was conducted to understand the statistical sianitı $\sim$ ice the possible relationship between the DBPFP concentrations and those of the in diviuiual MW fractions as determined by the LC-OCD analysis. To increase the statisticai nov er and the ability of the analysis to find relationships between the variables, the sa،n, ie size was expanded to include the data

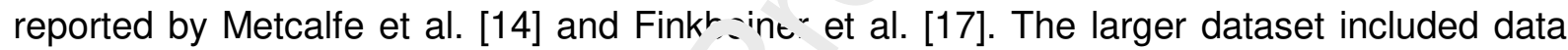
points from lowland river, upland river arı' reservoir source waters as well as the lowland river and reservoir sources pertaining in the current study. The ANOVA showed MW fractions $>350 \mathrm{~g} / \mathrm{mol}$ to have a s'at stıally significant impact on THM and HAA formation (PValues below 0.05 for the 95\% : nnfidence interval) (Fig S2).

The adjusted coefficit. ${ }^{+}$ui determination $\left(R^{2}{ }_{\text {adj }}\right)$ values for the multiple linear regressions were very close to the predicted coefficients of determination $\left(R_{\text {pred }}^{2}\right)$ for the THMs and HAAs (92.5\% vs $90.4 \%$ for THMs and $89.7 \%$ vs $86.4 \%$ for HAAs) (Table 2). The high $\mathrm{R}_{\text {adj }}^{2}$ value suggests that LC-OCD results can potentially be used to predict DBPFP if a validated method is developed, and that the high goodness of the fit was not due to the high number of predictors (three MW groups) [47]. Running the analysis with all the MW fractions did not improve the determination coefficient, verifying that the smallest fraction had no statistically significant impact on DBP formation. The fact that both coefficients of regression were similar also supported the fact that the analysis was not overfitted. 
Table 2. Multiple linear regression analysis summary

\begin{tabular}{lccccl}
\hline Source data & Predictor & $\mathbf{S}$ & $\mathbf{R}_{\text {adj }}^{2}$ & $\mathbf{R}_{\text {pred }}^{2}$ & Regression equation \\
\hline All studies $^{*}$ & THMs & 137 & $92.5 \%$ & $90.4 \%$ & THM $=153.6 \mathrm{MW} 1+189.5 \mathrm{MW} 2-270.9 \mathrm{MW} 3$ \\
& HAAs & 252 & $89.7 \%$ & $86.4 \%$ & HAA $=301.8 \mathrm{MW} 1+321.2 \mathrm{MW} 2-683 \mathrm{MW} 3$
\end{tabular}

MW1: > 10,000 g/mol; MW2: 1,000 g/mol MW; MW3: 300-500 g/mol MW

$S$ is the standard deviation of the data points around the fitted values

${ }^{*}$ Data from this study and those extracted from Metcalfe et al. [14] and Finkbeiner et al. [17]

As a result of the ANOVA and multiple linear regression analvi- $\mathrm{l}$ is therefore reasonable to assume that there is a link between molecular weight $f$ aci ins and chemical functionality within the fractions, since the latter is directly linkei to DBPs. The most statisticallysignificant MW fractions must thus contain organic $\_-\cdots$. ppounds with chemical functionality more conducive to DBP formation than ot 'e. ractions. In particular, the regression coefficients for the two largest MW fracti ns we $ə$ positive (Table 2), suggesting that as their concentrations increase, so does the formaiion potential for THMs, and more so for HAAs since the coefficients are greater ( $3(2$ and 321 for THMFP vs 154 and 190 for HAAFP). Specifically, the $>10,000 \mathrm{~g} / \mathrm{mol}+$ acıin is associated with organic material such as proteins, peptides and polysaccharide. wi:ich has been previously linked to DBP formation [48-50], whilst humic-like substar ve: (Ine $\sim 1000 \mathrm{~g} / \mathrm{mol}$ fraction) are known to have a high propensity to form DBPs [51]. On 1 e contrary, the regression coefficient for the organic matter group with MW between 300-500 $\mathrm{g} / \mathrm{mol}$ was negative for both THMs and HAAs, indicating that in this case, as the concentration of this fraction increased, the THMFP and HAAFP decreased instead. This could mean, and in line with the explanation suggested in Section 3.3, that building blocks of humic acids consume chlorine or hypobromous acid formed from $\mathrm{HOCl}$ and $\mathrm{Br}^{-}$to produce intermediates, but that these intermediates are not converted to either THMs or HAAs, but to other unmonitored DBPs. Further studies using high resolution mass spectrometry (HRMS) or Fourier Transform Infrared (FTIR) can provide additional information on the chemical functionality linking to DBP formation. 
The outcomes of the LC-OCD analysis indicate that, notwithstanding the complexities of the halogenation chemistry affecting the comparative concentrations yields of the chlorinated and brominated DBPs (Section 3.3), the total DBPFP can be estimated from the MW fractions $(\mathrm{MW}>350 \mathrm{~g} / \mathrm{mol}$ ) as determined from LC-OCD analysis. This information can be useful to characterise water sources and identify potential DBP risks as well as target treatment technology to remove particular MW fractions.

A review of published correlations for DBPFP vs DOC (or, in sne sase [52], dissolved organic nitrogen, DON) concentration for raw waters reveals the $2^{2} v$ llues to generally fall between 0.71 and 0.79 (Table 3); outliers of 0.65 and 0.85 for $-:$ ' $N_{1} \cdot{ }^{-P}$ and HAAFP, respectively were determined for the correlation against DON for a hir, inly polluted source [52]. These reported $R^{2}$ values are substantially lower than the vilis of 0.90 or more produced from the regression analysis based on molecular we yht fractions used in the current study. They are also higher than $R^{2}$ values of 0.7 s.78 reported using fluorescence excitation/emission matrices for a similarly extensive datr $s \in \iota[53,54]$. The $R^{2}$ values for the THMFP and HAAFP correlations in this study are $0 y_{i}$ and 0.90 respectively (Table 3 ), compared with 0.74 and 0.71 respectively for the classic $\urcorner 1$ correlation against $\mathrm{DOC}$ concentration.

Table 3. jummary of DBPFP ( $\mu \mathrm{g} / \mathrm{L})$ vs concentration $(\mathrm{mg} / \mathrm{L})$

\begin{tabular}{l|lcccc}
\hline Data source/reference & Source water & \multicolumn{2}{c}{ THMFP } & \multicolumn{2}{c}{ HAAFP } \\
& & Slope & $R^{2}$ & Slope & $R^{2}$ \\
\hline Xu et al. [52], DBPFP vs DON & Huangpu River & 680 & 0.64 & 750 & 0.85 \\
Pifer \& Fairey [53], THMFP vs DOC & Various US, surface \& ground & 78 & 0.75 & - & - \\
Golea et al. [55], DBPFP vs DOC & Scottish surface & 149 & 0.79 & 216 & 0.74 \\
This study ${ }^{*}$, DBPFP vs DOC & UK surface & $\mathbf{1 2 1}$ & $\mathbf{0 . 7 4}$ & $\mathbf{2 3 6}$ & $\mathbf{0 . 7 1}$ \\
This study ${ }^{*}$, DBPFP vs LC-OCD data & UK surface & - & $\mathbf{0 . 9 3}$ & - & $\mathbf{0 . 9 0}$ \\
\hline
\end{tabular}

*Data from this study and those extracted from Metcalfe et al. [14] and Finkbeiner et al. [17] 


\section{Conclusions}

An analysis of DBPFP of a raw and treated UK surface waters has been conducted, employing both chemical (sorption-based) and physical (liquid chromatography organic carbon detection, LC-OCD) fractionation for organic matter characterisation. The selected raw waters were of similar MW distribution, but differed with respect to both their organic chemistry and bromide content. The impact of the higher bromide concentration was to increase the proportion of brominated DBP species whilst decreasing the total concentration, consistent with reported studies on UK surface waters but $r_{1}{ }^{+}$with those for other water types. This effect has been attributed to the fact that orgar ' $-\mathrm{m}$ atter reacted with $\mathrm{HOBr}^{-}$to produce intermediates, but that these intermediates wer 3 , nt jonverted to brominated THMs or HAAs as readily as the chlorinated intermedizes. This highlights the importance of monitoring unknown DBP intermediates and furthar research on their potential risk.

An ANOVA of the MW fractions againsı T. AMFP and HAAFP showed that only MW $>350$ $\mathrm{g} / \mathrm{mol}$ were statistically significant in thc formation of DBPs, and a multiple linear regression of DBP concentration against the ron $\bullet$. Itration of individual MW fractions determined by LCOCD provided a strong corre! tior $\left(R^{2}=0.90-0.93\right)$, indicating that LC-OCD analysis alone could be used to predict DE ${ }^{D F F}$ with reasonable accuracy, if a validated model is developed. The LC-OCD analy is off rs the potential for rapid assessment and optimisation of treatability of organics $:$ ough quantifying the key MW fractions. The method represents a substantial improvement in precision of predicted DBPFP based on DOC, and is less laborious than chemical fractionation for quantifying the hydrophobic and hydrophilic organic content. It also appears to be unaffected by the vagaries of bromide-related DBPFP. However, the work would need to be extended to surface waters from multiple locations globally to provide a true assessment of its general efficacy. 


\section{ACKNOWLEDGEMENTS}

This work was supported by Anglian Water Services (UK). 


\section{References}

[1] J.G. Jacangelo, J. DeMarco, D.M. Owen, S.J. Randtke, Selected processes for removing NOM: An overview, J. / Am. Water Work. Assoc. 87 (1995) 64-77. https://doi.org/10.1002/j.1551-8833.1995.tb06302.x.

[2] J. Zeng, S. Chen, K. Wan, J. Li, D. Hu, S. Zhang, X. Yu, Study of biological up-flow roughing filters designed for drinking water pretreatment in rural areas: using ceramic media as filter material, Environ. Technol. (United Kingdom). In Press (2020). https://doi.org/10.1080/09593330.2018.1530304.

[3] D.M. Golea, P. Jarvis, B. Jefferson, G. Moore, S. S ^ııriand, S.A. Parsons, S.J. Judd, Influence of granular activated carbon media prop stties on natural organic matter and disinfection by-product precursor removal from vinking water, Water Res. 174 (2020) 115613. https://doi.org/10.1016/j.watres.ı́ 0’_0 115613.

[4] J.S. Yang, D.X. Yuan, T.P. Wen , P ot study of drinking water treatment with GAC, O3/BAC and membrane prousses in Kinmen Island, Taiwan, Desalination. 263 (2010) 271-278. https://doi.o. g/ll . 1016/j.desal.2010.06.069.

[5] J.P. Croue, D. Violleau L. i abouyrie, Disinfection by-product formation potentials of hydrophobic and hy ${ }^{\top}$ ropı ilic natural organic matter fractions: a comparison between low and high 'יur, ic v ater, in: A.C. Society (Ed.), 761, ACS Symposium, 2000: pp. $139-153$.

[6] A. Phetrak, J. Lohwacharin, S. Takizawa, Analysis of trihalomethane precursor removal from sub-tropical reservoir waters by a magnetic ion exchange resin using a combined method of chloride concentration variation and surrogate organic molecules,

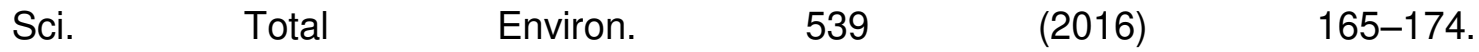
https://doi.org/10.1016/j.scitotenv.2015.08.111.

[7] M. Sillanpää, M.C. Ncibi, A. Matilainen, M. Vepsäläinen, Removal of natural organic matter in drinking water treatment by coagulation: A comprehensive review, 
Chemosphere. 190 (2018) 54-71. https://doi.org/10.1016/j.chemosphere.2017.09.113.

[8] K. Watson, M.J. Farré, N. Knight, Enhanced coagulation with powdered activated carbon or MIEX® secondary treatment: A comparison of disinfection by-product formation and precursor removal, Water Res. 68 (2015) 454-466. https://doi.org/10.1016/j.watres.2014.09.042.

[9] A. Andersson, E. Lavonen, M. Harir, M. Gonsior, N. Hertkorn, P. Schmitt-Kopplin, H. Kylin, D. Bastviken, Selective removal of natural organic matter during drinking water production changes the composition of disinfection by-pљducts, Environ. Sci. Water Res. Technol. 6 (2020) 779-794. https://doi.org/10.1n3i'^^'jew00931k.

[10] I. Levchuk, J.J. Rueda Márquez, M. Sillanpää, Removal of natural organic matter (NOM) from water by ion exchange - A rt :w, Chemosphere. (2018) 90-104. https://doi.org/10.1016/j.chemosphere.2(17.1).101.

[11] P.C. Singer, K. Bilyk, Enhanced co:gulation using a magnetic ion exchange resin, Water Res. 36 (2002) 4009-4し.?. https://doi.org/10.1016/S0043-1354(02)00115-X.

[12] T.H. Boyer, P.C. Singer, Ben $h$ scale testing of a magnetic ion exchange resin for removal of disinfection by-product precursors, Water Res. 39 (2005). https://doi.org/10.10: $9 /$ j.h atres.2005.01.002.

[13] R.S. Kingsbury, +... Singer, Effect of magnetic ion exchange and ozonation on disinfection by-product formation, Water Res. 47 (2013) 1060-1072. https://doi.org/10.1016/j.watres.2012.11.015.

[14] D. Metcalfe, C. Rockey, B. Jefferson, S. Judd, P. Jarvis, Removal of disinfection byproduct precursors by coagulation and an innovative suspended ion exchange process, Water Res. 87 (2015) 20-28. https://doi.org/10.1016/j.watres.2015.09.003.

[15] J.N. Apell, T.H. Boyer, Combined ion exchange treatment for removal of dissolved organic matter and hardness, Water Res. 44 (2010) 2419-2430. https://doi.org/10.1016/j.watres.2010.01.004. 
[16] B.R. Johnson, T.B. Eldred, A.T. Nguyen, W.M. Payne, E.E. Schmidt, A.Y. Alansari, J.E. Amburgey, J.C. Poler, High-Capacity and Rapid Removal of Refractory NOM Using Nanoscale Anion Exchange Resin, ACS Appl. Mater. Interfaces. 2016 (2016) 18540-18549. https://doi.org/10.1021/acsami.6b04368.

[17] P. Finkbeiner, J. Redman, V. Patriarca, G. Moore, B. Jefferson, P. Jarvis, Understanding the potential for selective natural organic matter removal by ion $\begin{array}{lllll}\text { exchange, } & \text { Water } & \text { Res. } & 146 & \text { (2018) 263 }\end{array}$ https://doi.org/10.1016/j.watres.2018.09.042.

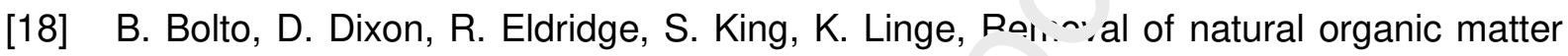
by ion exchange, Water Res. 36 (2002) 5057 j0bū. https://doi.org/10.1016/S00431354(02)00231-2.

[19] M.R.D. Mergen, B. Jefferson, S.A. Pars गr.s, P. Jarvis, Magnetic ion-exchange resin treatment: Impact of water type ^nc re: https://doi.org/10.1016/j.watres.2007. . 1.032.

[20] O. Gibert, N. Pages, X. Bern،.t J.L. Cortina, Removal of dissolved organic carbon and bromide by a hybrid MIF.^ 'Iltrafiltration system: Insight into the behaviour of organic fractions, Chem. Ena. J. 212 (2017) 59-67. https://doi.org/10.1016/j.cej.2016.11.120.

[21] Y. Tang, X. Ling, M. Wu, S. Yang, N. Gao, B. Xu, S. Dutta, Bibliometric review of research trends $\sim r$. disinfection by-products in drinking water during 1975-2018, Sep. Purif. Technol. 241 (2020) 116741. https://doi.org/10.1016/j.seppur.2020.116741.

[22] E.H. Goslan, P. Jarvis, B. Jefferson, J. Fawell, Identification of treatment conditions which minimise DBP formation. UKWIR Report 1234., 2020.

[23] M. Soyluoglu, M.S. Ersan, M. Ateia, T. Karanfil, Removal of bromide from natural waters: Bromide-selective vs. conventional ion exchange resins, Chemosphere. 238 (2020) 124583. https://doi.org/10.1016/j.chemosphere.2019.124583.

[24] P. Finkbeiner, G. Moore, T. Tseka, T.T.I. Nkambule, L. De Kock, B. Jefferson, P. 
Jarvis, Interactions between Organic Model Compounds and Ion Exchange Resins, Environ. Sci. Technol. 53 (2019) 9734-9743. https://doi.org/10.1021/acs.est.9b02139.

[25] A. Szczuka, K.M. Parker, C. Harvey, E. Hayes, A. Vengosh, W.A. Mitch, Regulated and unregulated halogenated disinfection byproduct formation from chlorination of saline groundwater, Water Res. $122 \quad$ (2017) 633-644. https://doi.org/10.1016/j.watres.2017.06.028.

[26] B. Zhang, Q. Xian, J. Lu, T. Gong, A. Li, J. Feng, Evaluation of DBPs formation from SMPs exposed to chlorine, chloramine and ozone, J. W Wa ${ }^{+}$.r Health. 15 (2017) 185195. https://doi.org/10.2166/wh.2016.136.

[27] M. Cai, W. Liu, W. Sun, Formation and spec.?tion of disinfection byproducts in desalinated seawater blended with treatea úrinking water during chlorination, Desalination. 437 (2018) 7-14. https://do c.g 10.1016/j.desal.2018.02.009.

[28] S. Sutherland, S.A. Parsons, A. Da'eshkhah, P. Jarvis, S.J. Judd, THM precursor rejection by UF membranes trc गting Scottish surface waters, Sep. Purif. Technol. 149 (2015) 381-388. https://doi.o. g//1 . 1016/j.seppur.2015.06.009.

[29] J. Wang, T. Gong, Q Xia.', Formation of haloacetic acids from different organic precursors in swimrring pool water during chlorination, Chemosphere. 247 (2020) 125793. https:,'/o. orc '10.1016/j.chemosphere.2019.125793.

[30] T. Bond, O. Henrret, E.H. Goslan, S.A. Parsons, B. Jefferson, Disinfection byproduct formation and fractionation behavior of natural organic matter surrogates, Environ. Sci. Technol. 43 (2009) 5982-5989. https://doi.org/10.1021/es900686p.

[31] L. Moberg, B. Karlberg, An improved N,N'-diethyl-p-phenylenediamine (DPD) method for the determination of free chlorine based on multiple wavelength detection, Anal. Chim. Acta. (2000). https://doi.org/10.1016/S0003-2670(99)00780-1.

[32] C.M.M. Bougeard, E.H. Goslan, B. Jefferson, S.A. Parsons, Comparison of the disinfection by-product formation potential of treated waters exposed to chlorine and 
$\begin{array}{lllll}\text { monochloramine, } & \text { Water } & \text { Res. } & 44 & \text { (2010) }\end{array}$ https://doi.org/10.1016/j.watres.2009.10.008.

[33] S.A. Huber, A. Balz, M. Abert, W. Pronk, Characterisation of aquatic humic and nonhumic matter with size-exclusion chromatography - organic carbon detection - organic nitrogen detection (LC-OCD-OND), Water Res. 45 (2011) 879-885. https://doi.org/10.1016/j.watres.2010.09.023.

[34] H. Humbert, H. Gallard, V. Jacquemet, J.P. Croué, Combination of coagulation and ion exchange for the reduction of UF fouling properties ot $\_$high DOC content surface water, Water Res. 45 (2007) 879-885. https://doi.orr/1し. 1'J16/j.watres.2007.06.009.

[35] S. Velten, D.R.U. Knappe, J. Traber, H.P. Kaiser, ¿ ' von Gunten, M. Boller, S. Meylan, Characterization of natural organic matter ac - ption in granular activated carbon $\begin{array}{lllll}\text { adsorbers, } & \text { Water } & \text { Res. } & 45 & \text { (2011) 3951-3959. }\end{array}$

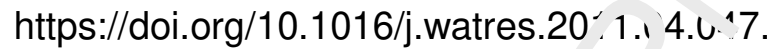

[36] E.R. Cornelissen, N. Moreau, “'G. Siegers, A.J. Abrahamse, L.C. Rietveld, A. Grefte, M. Dignum, G. Amy, L.P. We: $:$ sl: , Selection of anionic exchange resins for removal of natural organic matter (NUM) fractions, Water Res. 42 (2008) 413-423. https://doi.org/10.1016/J. .'atres.2007.07.033.

[37] P. Finkbeiner, ᄀ. , 10o e, R. Pereira, B. Jefferson, P. Jarvis, The combined influence of hydrophobicity, ch'arge and molecular weight on natural organic matter removal by ion exchange and coagulation, Chemosphere. $238 \quad$ (2020) 124633. https://doi.org/10.1016/j.chemosphere.2019.124633.

[38] D. Ghernaout, Coagulation and Chlorination of NOM and Algae in Water Treatment: A Review, Int. J. Environ. Monit. Anal. 2 (2014) 23-24. https://doi.org/10.11648/j.ijema.s.2014020601.14.

[39] A.D. Nikolaou, T.D. Lekkas, The Role of Natural Organic Matter during Formation of Chlorination By-products: A Review, Acta Hydrochim. Hydrobiol. 29 (2001) 63-77. 
https://doi.org/10.1002/1521-401x(200109)29:2/3<63::aid-aheh63>3.3.co;2-3.

[40] A. Bhatnagar, M. Sillanpää, Removal of natural organic matter (NOM) and its constituents from water by adsorption - A review, Chemosphere. 166 (2017) 497-510. https://doi.org/10.1016/j.chemosphere.2016.09.098.

[41] M. Kitis, T. Karanfil, J.E. Kilduff, A. Wigton, The reactivity of natural organic matter to disinfection by-products formation and its relation to specific ultraviolet absorbance, Water Sci. Technol. 43 (2001) 9-16. https://doi.org/10.2166/wst.2001.0067.

[42] K.M. Mok, H. Wong, X.J. Fan, Modeling bromide :ffects on the speciation of trihalomethanes formation in chlorinated drinking wa'or, Glob. NEST JournalGlobal NEST Int. J. 7 (2018) 301-319. https://doi.org/10.`n955/gnj.000334.

[43] J. Li, B. Moe, S. Vemula, W. Wang, X.F LI, Emerging Disinfection Byproducts, Halobenzoquinones: Effects of Isom?r- ctructure and Halogen Substitution on Cytotoxicity, Formation of Reacti e (xygen Species, and Genotoxicity, Environ. Sci. Technol. 50 (2016) 6744-675`. https://doi.org/10.1021/acs.est.5b05585.

[44] J. Jiang, J. Han, X. Zhang, N'onhalogenated Aromatic DBPs in Drinking Water Chlorination: A Gap beiwet? NOM and Halogenated Aromatic DBPs, Environ. Sci. Technol. 54 (2020) 1̧46. ittps://doi.org/10.1021/acs.est.9b06403.

[45] X.F. Li, W.A. Mıı -h, n. Inking Water Disinfection Byproducts (DBPs) and Human Health Effects: Multidiscıplinary Challenges and Opportunities, Environ. Sci. Technol. 52 (2018) 1681-1689. https://doi.org/10.1021/acs.est.7b05440.

[46] A.A. Cuthbertson, S.Y. Kimura, H.K. Liberatore, R.S. Summers, D.R.U. Knappe, B.D. Stanford, J.C. Maness, R.E. Mulhern, M. Selbes, S.D. Richardson, Does Granular Activated Carbon with Chlorination Produce Safer Drinking Water? from Disinfection Byproducts and Total Organic Halogen to Calculated Toxicity, Environ. Sci. Technol. (2019). https://doi.org/10.1021/acs.est.9b00023.

[47] P. Yin, X. Fan, Estimating R-squared Shrinkage in Multiple Regression: A Comparison 
of Different Analytical Methods.(Statistical Data Included), J. Exp. Educ. 69 (2001) 203-224.

[48] J. Fang, J. Ma, X. Yang, C. Shang, Formation of carbonaceous and nitrogenous disinfection by-products from the chlorination of Microcystis aeruginosa, Water Res. 44 (2010) 1934-1040. https://doi.org/10.1016/j.watres.2009.11.046.

[49] J. Huang, N. Graham, M.R. Templeton, Y. Zhang, C. Collins, M. Nieuwenhuijsen, A comparison of the role of two blue-green algae in THM and HAA formation, Water Res. 43 (2009) 3009-3018. https://doi.org/10.1016/j.watres ?.009.04.029.

[50] J.L. Lin, A.R. Ika, Minimization of halogenated D'sr grecursors by enhanced PACl coagulation: The impact of organic molecule tration changes on DBP precursors destabilization with Al hydrates, Sci. רし: Environ. 703 (2020) 134936.

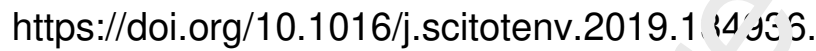

[51] A.D. Nikolaou, S.K. Golfinopoul's, '.D. Lekkas, M.N. Kostopoulou, DBP levels in chlorinated drinking water: Eínct of numic substances, Environ. Monit. Assess. 93 (2004) 301-319. https://doi.o. g'/l . 1023/B:EMAS.0000016798.53163.43.

[52] B. Xu, T. Ye, D.P. Li, C “' R.', Y.L. Lin, S.J. Xia, F.X. Tian, N.Y. Gao, Measurement of dissolved organic ni: *nge , in a drinking water treatment plant: Size fraction, fate, and relation to Wćtar xus lity parameters, Sci. Total Environ. 409 (2011) 1116-1122. https://doi.org/1C ${ }^{1}$ J16/j.scitotenv.2010.12.016.

[53] A.D. Pifer, J.L. Fairey, Suitability of organic matter surrogates to predict trihalomethane formation in drinking water sources, Environ. Eng. Sci. 31 (2014). https://doi.org/10.1089/ees.2013.0247.

[54] L. Yang, D. Kim, H. Uzun, T. Karanfil, J. Hur, Assessing trihalomethanes (THMs) and $\mathrm{N}$-nitrosodimethylamine (NDMA) formation potentials in drinking water treatment plants using fluorescence spectroscopy and parallel factor analysis, Chemosphere. 121 (2015) 84-91. https://doi.org/10.1016/j.chemosphere.2014.11.033. 
[55] D.M. Golea, A. Upton, P. Jarvis, G. Moore, S. Sutherland, S.A. Parsons, S.J. Judd, THM and HAA formation from NOM in raw and treated surface waters, Water Res. 112 (2017) 226-235. https://doi.org/10.1016/j.watres.2017.01.051. 
Credit Author statement:

\begin{tabular}{|c|c|c|c|c|c|c|c|}
\hline Contribution & $\begin{array}{l}\text { Irene } \\
\text { Carra }\end{array}$ & $\begin{array}{l}\text { Javier } \\
\text { Fernandez } \\
\text { Lozano }\end{array}$ & $\begin{array}{l}\text { Scott } \\
\text { Johannesen }\end{array}$ & $\begin{array}{l}\text { Max } \\
\text { Godart- } \\
\text { Brown }\end{array}$ & $\begin{array}{l}\text { Emma H. } \\
\text { Goslan }\end{array}$ & $\begin{array}{l}\text { Peter } \\
\text { Jarvis }\end{array}$ & $\begin{array}{l}\text { Simon } \\
\text { Judd }\end{array}$ \\
\hline Conceptualization & $\mathrm{X}$ & & & & & $\mathrm{X}$ & \\
\hline Methodology & $\mathrm{X}$ & $\mathrm{X}$ & $\mathrm{X}$ & $\mathrm{X}$ & & & \\
\hline Validation & $\mathrm{x}$ & & & & $\mathrm{X}$ & $\mathrm{X}$ & $\mathrm{x}$ \\
\hline Formal analysis & $\mathrm{X}$ & $\mathrm{x}$ & $\mathrm{X}$ & $\mathrm{X}$ & & & \\
\hline Investigation & & $\mathrm{X}$ & $\mathrm{x}$ & $\mathrm{x}$ & & & \\
\hline Resources & $\mathrm{x}$ & & & & & & \\
\hline Data Curation & $\mathrm{X}$ & $\mathrm{X}$ & $\mathrm{X}$ & $\mathrm{x}$ & & & \\
\hline $\begin{array}{l}\text { Writing - Original } \\
\text { Draft }\end{array}$ & $\mathrm{x}$ & & & & & & $\mathrm{x}$ \\
\hline $\begin{array}{l}\text { Writing - Review } \\
\text { \& Editing }\end{array}$ & $\mathrm{x}$ & & & & $\mathrm{x}$ & $\mathrm{x}$ & $\mathrm{x}$ \\
\hline Visualization & $\mathrm{x}$ & & & & & & $\mathrm{x}$ \\
\hline Supervision & $\mathrm{x}$ & & & & & $\mathrm{X}$ & \\
\hline $\begin{array}{l}\text { Project } \\
\text { administration }\end{array}$ & $\mathrm{x}$ & & & & & & \\
\hline $\begin{array}{l}\text { Funding } \\
\text { acquisition }\end{array}$ & $\mathrm{X}$ & & & & & & \\
\hline
\end{tabular}




\section{Declaration of interests}

$\bigotimes$ The authors declare that they have no known competing financial interests or personal relationships that could have appeared to influence the work reported in this paper.

$\square$ The authors declare the following financial interests/personal relationships which may be considered as potential competing interests: 


\section{Graphical Abstract}
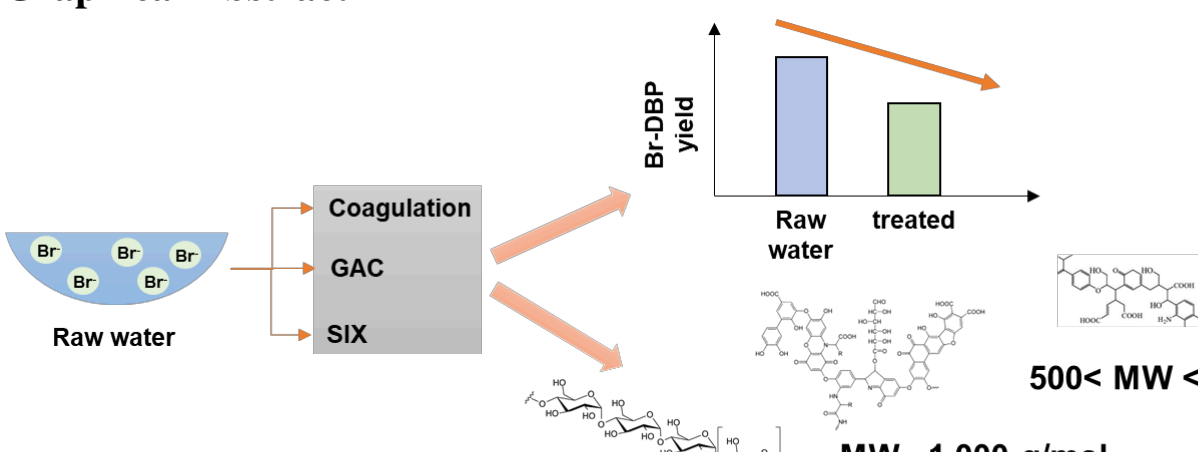

$500<\mathrm{MW}<300 \mathrm{~g} / \mathrm{mol}$

\section{MW 1,000 g/mol}

$M W>10,000 \mathrm{~g} / \mathrm{mol}$

THMs

HAAs

b.-intermediate DBPs 


\section{Highlights}

- Application of suspended ion exchange (SIX) to UK lowland waters

- Treatment efficacy assessed as minimisation of DBP concentration and yield

- Moderate/high-bromide waters studied; efficacy compared with conventional processes

- Molecular weight $>350 \mathrm{~g} / \mathrm{mol}$ impacted THM and HAA formation

- Increased bromide level in feedwater led to decreased DBP concentration and yield

\section{Highlights Reviewed}

- Molecular weight $>350 \mathrm{~g} / \mathrm{mol}$ impacted THM and HAA formation

- Increased bromide level in feedwater led to decreased THM and HAA concentration

- LC-OCD was used to predict THM and HAA formation potential $\left(R^{2}=0.90-0.93\right)$

- Organics with 300-500 $\mathrm{g} / \mathrm{mol}$ may form intermediates not transformed to THMs or HAAs 